Gunnhildur Óskarsdóttir is an associate professor of education at the School of Education, University of Iceland and currently the Head of Faculty of Teacher Education. Her research interests include children's learning and concept development, science education, classroom research, and teacher education.

Jón Torfi Jónasson is professor of education in the Faculty of Teacher Education, at the School of Education, University of Iceland. For many years he taught Cognitive Psychology and the Psychology of Learning at the University of Iceland. He has been the Dean of the Faculty of Social Science and then the Dean of the School of Education at the University of Iceland. Recently he has done research on professional development of teachers and what elements within the educational edifice resist change.

GUNNHILDUR ÓSKARSDÓTTIR

Department of Teacher Education, School of Education, University of Iceland, Iceland gunn@hi.is

JÓN TORFI JÓNASSON

Department of Teacher Education, School of Education, University of Iceland, Iceland jtj@hi.is

\title{
Quiet pupils can be effective learners
}

\section{Abstract}

This paper investigates the importance for pupils' learning of being generally visibly active participant in a classroom discussion. A class of six year-old pupils was taught about the human skeletal system and other organs. To determine what they had learnt, they were asked to produce drawings before and after the course of teaching. The pupils' participation in the class discussion during the course of teaching was given values on a scale from 1-8, the most talkative receiving the value 1 and the least talkative (or most quiet) the value 8 . The study showed that the less talkative the pupils were in the discussion the more they gained from the teaching. The results could not be accounted for by ceiling effects and similar patterns obtained across the materials used support the robustness of the findings. The study suggests that it cannot be assumed that participating in classroom discussion during the learning process is a necessary precondition for learning.

\section{INTRODUCTION}

Taking part in discussions seems to be commonly used as a criterion for being active in the classroom (Collins, 1996; Myhill \& Brackley, 2004). There also seems to be a tendency in the literature on activity in the classroom to assume that children who are quiet in this respect are not learning as much as the children who take part in discussion (Burns \& Myhill, 2004; Chi, Siler, Jeong, Yamauchi, \& Haussmann, 2001; Fisher, 2005; Ogden, 2000; Reda, 2009). The literature shows that both of these assumptions may be questioned.

\section{THE OUESTION OF ACTIVITY}

Bruner and Haste (1987) argue that being active helps children to construct their own view of the world around them, personalise the experience and apply it in a way that makes sense to them individually; thus activity is seen as a prerequisite for learning. But how does one define 'activity' as a construct independent of the construct 'learning'? The substantiation of the claim that activity is a 
precondition for learning requires the two constructs to be defined independently, otherwise activity cannot be distinguished from learning and its definition becomes circular vis-à-vis the learning construct.

What are the characteristics of activity? A child can be an active listener, and in this sense be actively, i.e. fruitfully, listening to a story, watching a demonstration, a picture or a video, or be affected by listening to a conversation or an explanation, without manifesting any external signs of activity. And children can also be active by discussing with or questioning their peers or the teacher (Wilson \& Myers, 2000). Central to the constructivist view of learning is the notion that the learner is active in the process of taking in information and building knowledge and understanding and that the learner can only make sense of new knowledge in terms of his or her existing understanding (Cornu, Peters, \& Collins, 2003; Keogh \& Naylor, 1996). Thus, being active can include a variety of actions that can be overt or inferred; the child can be working alone or in collaboration with others and be participating in either case, both 'physically' active in terms of visibly doing something and also 'cognitively' active by thinking and reflecting.

Constructivist perspectives have had a significant impact on recent research in science education, but there has been some debate and criticism of how the constructivist view is presented and practised which is evident in the different chapters in Tobias and Duffy (2009). Osborne (1996) suggests that there may also be important individual differences to the effect that the same or similar kind of activity and thus approach to teaching may not benefit all students equally. Activity which may be beneficial to learning may thus vary between individuals.

\section{INTERACTION - LEARNING FROM EACH OTHER AND FROM THE TEACHER}

Much of the literature about interaction in the classroom builds on the views expressed earlier, that interaction in the form of a discussion between learners and the teacher is crucial for cognitive development. Research into the nature of classroom discussion has shown that it is dominated by statements and questions from the teacher (Burns \& Myhill, 2004; Myhill \& Brackley, 2004). Burns and Myhill (2004) argue that this kind of discourse situation does not support or scaffold pupils' learning because the interaction is largely a case of pupils participating upon request. It is therefore not interactive in the sense of engaging them in active talk that would facilitate them to create and develop their understanding. The rationale for the discourse is that pupils have to be visibly participating in order to learn. However, every child has his or her own store of experiences, ideas and knowledge that he or she uses to make sense of the world.

Bruner and Haste (1987) emphasise the social aspect of learning "[m]aking sense is a social process" (p.i). It is through 'knowledgeable others' that a child's potential for learning is revealed and these others can be parents, teachers, other adults, siblings, friends or peers (Bruner \& Haste, 1987; Fisher, 1995). Through interaction with peers or classmates, children are presented with points of view or ideas that differ from their own and thus may develop and change their existing ideas (Ogden, 200o). Chi et al., (2001) point out that learning does not only occur through direct personal participation in a dialogue. Some learning occurs through observing and overhearing others. However, a study on students' performance on a problem-solving task where one group did a task and participated in discussion with the tutor and another group overheard the dialogues of the participants showed that students who participated in discussion performed better than those who overheard, suggesting that explicit interaction facilitates performance (Chi et al., 2001).

Barnes (2008) discusses the importance of considering what kind of discussion is most important for understanding. He uses the term "exploratory talk" when young people are trying out ideas and modifying them as they speak, and defines it thus: "Exploratory talk is hesitant and incomplete because it enables the speaker to try out new ideas, to hear how they sound, to see what others make of them, to arrange information and ideas into different patterns" (p. 5). 
Mercer (1995, 2000) builds on Vygotsky (1978) and describes language as 'a social mode of thinking' and thus emphasises the social cultural perspective of learning where knowledge is jointly created and shared. Moreover, he points out that emphasis should be put on the use of language for thinking together "for collectively making sense of experience and solving problems" (Mercer, 2000, p. 1). Relatedly, Alexander (2004) claims that talk has always been one of the essential tools of teaching and the best teachers use talk successfully "with precision and flair" (p. 9). While Mercer and Littleton (2007) point out that it is through the interactive dialogue in the classroom that the teacher learns about children's ideas and understanding of a topic and this information can then be used for developing the topic and the lessons further.

Howe and Mercer (2007) discuss the educational significance of classroom interaction amongst children for their learning and cognitive development. They suggest that collaborative learning is of educational value and children are encouraged to pursue joint goals, explain their understanding and different points of view and attempt to reach consensus through discussion, which requires explicit involvement by the children. However, Howe and Mercer also point out that teachers need to do more than just provide group and pair-based activities as these do not necessarily provide productive interaction. For collaborative activity to be useful and productive, children need to be offered suitable tasks that encourage cooperation and group coherence rather than competitiveness. This is supported by e.g. Barnes (2008), Scott (2008) and Mercer and Dawes (2008) who all indicate that substantial research has mostly focused on exploring and recognizing children's ideas and the value of using these ideas to support and improve their learning. However, according to Keogh and Naylor (2004), much of the guidance on helping children to change and develop their ideas, is based on the assumption that children are willing to express their ideas and need to do so in order to learn. In line with this Collins discusses the frustration for a teacher of not being able to communicate with a group of quiet, withdrawn pupils (Collins, 1996). These pupils seemed unwilling and unable to join in the social and academic conversation that took place in the class. They rarely spoke in class and seemed reluctant to ask for help. Collins's concern for these quiet pupils stemmed from her belief that talk is central to children's cognitive and emotional development and that children develop their perception of themselves and the world through talk. According to Collins (1996), teachers assess and support children's learning by talking to them and listening to what they say and for pupils to be successful and make the most of learning opportunities, it is important that they become active participants in classroom discussion. Collins' view is in line with the views expressed earlier, that conversations between children and adults significantly aid cognitive development (Hedegaard, 1999; Myhill, 2003; Myhill \& Brackley, 2004; Ogden, 2000; Vygotsky, 1986).

Thus, there is a strong trend in the literature to support the importance of talk and shared discussion in the classroom as a prerequisite to learning. Harlen and Qualter (2004) suggest that "[c]hildren have to feel free to express their own ideas and ways of thinking, without fear that they are giving the 'wrong' answer" (Harlen \& Qualter, 2004 p.141). According to them, the teacher must establish a classroom climate in which children feel safe to express their ideas. Teachers can use various strategies to access children's ideas such as questioning, writings, drawings, concept maps, concept cartoons and discussion. Harlen and Qualter also point out that questioning and answering strategies are usually oral, but in some circumstances, it may be better for children to write down their ideas or to produce a drawing or set of drawings to express their ideas. This can provide the teacher with information about the full range of ideas in the class (Harlen \& Qualter, 2004). The fact that some pupils are reluctant to talk in the classroom and share their ideas, is therefore seen as a problem. However, a somewhat different position has also been taken. Reda (2009) discusses how some students often appear to resist the teacher's efforts to include them in classroom discussion and how their silence is considered as problematic and even disruptive: "the good student, the student who learns, is the 'active' student; active has become synonymous with highly vocal .... those quiet or silent students in our classrooms, then may appear to mark some sort of failure" (p. 5-6). However, Reda argues against the common view whereby silence is seen as something that must be overcome. She suggests 
that greater emphasis needs to be put on activities that highlight active listening as an integral part of a dialogue and of learning. Moreover, she even talks about reintroducing silence in the classroom, since "choosing to be silent allows for the active construction of one's perspective through considering other's insights" (p. 161). Thus, in light of the literature review and within the context of a study of how ideas about the body are formed, the research question addressed in this paper is: Is there a relationship between being visibly active in class discussion and learning?

\section{THE STUDY}

The study presented here is a part of a larger study about the development of children's ideas about the body. The larger study explored how and under what circumstances children's ideas about the body changed during the two first grades of elementary school (6 and 7 year-old children), in a 'normal' classroom setting in an Icelandic elementary school. The focus was on children's ideas about the structure, location and function of bones and other organs and on how changes in pupils' ideas were affected by the curriculum, teaching methods, teaching materials and teacher-pupil and peer interactions. Special attention was given to how visibly active the pupils were participating in verbal activities in the classroom (Óskarsdóttir, 2006). Here we focus on the relationship between these verbal activities and how much the children learned. The criteria we used as basis for our judgement mainly entailed verbal activities, that is, taking part in class discussion or sharing ideas on the topic of learning as presented by the teacher.

\section{THE SAMPLE}

An elementary school in Reykjavík, Iceland, which was known for good science teaching was chosen to take part in the study about the nature of science teaching and the development of knowledge (Óskarsdóttir, 2006). The study presented here is a part of this larger project. The class consisted of twenty, 6 year old 1st grade children: ten boys and ten girls, a slightly larger than a typical class size for this age group. The average class size within primary education in Iceland is 18 students, which is somewhat lower than the OECD average of 21.6 (Indicator D2, OECD, 2010). The data for the whole project was obtained during normal class sessions when the class teacher was teaching about the human body with as little interference from the researcher as possible. All the data points for the study reported here were available for 15 pupils, and this was used as a criterion to include them in the analysis.

\section{METHOD}

The study reported here used classroom observations of the children's activities during class sessions with focus on the human body and analysis of the children's drawings. Specially designed rating scales were used to obtain a quantitative view of the children's ideas as put forward in their drawings.

\section{Materials - drawings}

A wide range of teaching methods were used in the lessons on the human body. The materials dealt with bone structure and the location of bones in the body as well as the structure and location of other organs. A typical lesson started with an open question, followed by a discussion where the teacher tried to involve the children, e.g. by encouraging them to explore their senses. For example, pupils walked up and down stairs without bending their knees to see what it would be like not to have any joints and listened to each other's heartbeats through a stethoscope before and after exercise. The children also did some interactive tasks on the Internet where they were asked, in pairs, to put the organs i.e. the brain, heart, lungs, stomach, colon and intestine, liver and kidneys in their right places. All the children took part in these activities.

Before being taught about the human body, the children were asked to draw the bones of the human body on a special premade outline of the body. After a lesson about bones, including their locations, they were asked to repeat the drawing task. The same procedure was used in connection with teaching 
about other human organs. There was an interval of two weeks between the pre-teaching and postteaching drawings of the bones with five 40 min lessons, in which the focus was on the bones and then an interval of four weeks for the drawings of the other organs, again with five lessons on the organs of the body.

\section{The drawing rating scales}

The children's drawings of the bones were analysed by using a 7 level scale developed by Reiss and Tunnicliffe (Reiss \& Tunnicliffe, 1999; Tunnicliffe \& Reiss, 1999) which assessed how well the children showed their knowledge of the skeleton (the basic dependent variable). The drawings of the other organs were analysed using a modified scale based on the Reiss and Tunnicliffe's scale, which had 8 levels. In the analysis the organ data was re-scaled to a seven point scale to make both scales comparable.

\section{The quietness scale}

The criteria used to characterise visible activity mainly entailed verbal actions of each child related to learning, that is, taking part in discussion and sharing ideas about issues regarding the human body. Thus, the term 'visible activity' in the present context means being visibly active in discussion of the topic being taught. The classroom observer (first author) soon noticed that some of the children never expressed themselves or took part in classroom discussion, whereas four or five children took a particularly active part in discussion. In the light of this a quietness scale with eight levels was constructed in order to gauge whether the development of the ideas about bones and other organs could be related to participation in class discussion. The scale is a nominal rank scale, where the most visibly active children were classified as having the value 1 , the least active (most quiet) had the value 8 , and the other children were given values that ranged from 2 to 7 . The grading of the children on the quietness scale was done independently by the class teacher and the classroom observer. Only for three pupils the teacher and the observer initially differed in terms of their grading but came subsequently to a joint agreed grading after reviewing video recordings of the observed lessons. The scale relates solely to participation in class discussion as judged by both the teacher and the observer. Because of the few data points, it is open to debate whether parametric tests are appropriate. It is noted that there are no serious outliers, which would require non-parametric tests. For correlation and main effects, both parametric and non-parametric approaches are used, but for an interaction test an ANOVA will be used. The principal analysis calculates the correlation between the learning gains by the children, as assessed by scoring their drawings before and after teaching, and their participation in class discussion, as assessed by the quietness scale. The interaction between learning and activity is also gauged by dividing the children into three activity groups on the quietness scale: the most visibly active group, Group 1, (quietness values 1-3), Group 2, the semi-active group (quietness values 4-5) and Group 3, the visibly passive group / the quiet children (quietness values, 6-8). Thus, we also probe the data using a $2 \times 2 \times 3$ design (time of testing $\mathrm{x}$ materials $\mathrm{x}$ activity group), where time of testing (the difference between time 1 and time 2 indicates learning) and materials (i.e. bones or other organs) are within subjects variables and activity level is a between subjects variable.

\section{RESULTS}

The overall gains for all the children are significant. Whether using a paired t-test $(t=7,276, d f=14$, $\mathrm{p}<0.001)$ or non-parametric tests, e.g. the Wilcoxon Signed Ranks Test, $(Z=-3,315, p<0.001)$, the difference between before and after scores was significant. Thus, learning took place. The question is whether it can be related to the observed level of activity. 'Quietness', the opposite of visible participation in class discussion, as it relates to the topic being taught is the independent variable being investigated, with performance on the bones and organ scales the dependent measures. For each child the learning gains were calculated by subtracting the level of knowledge before the teaching from the level after the teaching, as shown by the two scales (bones and organs) but also the average of these measures. 
The principal analysis is between the gains in understanding as calculated by the average and the visible activity as reflected in the quietness measure, see Fig. 1.

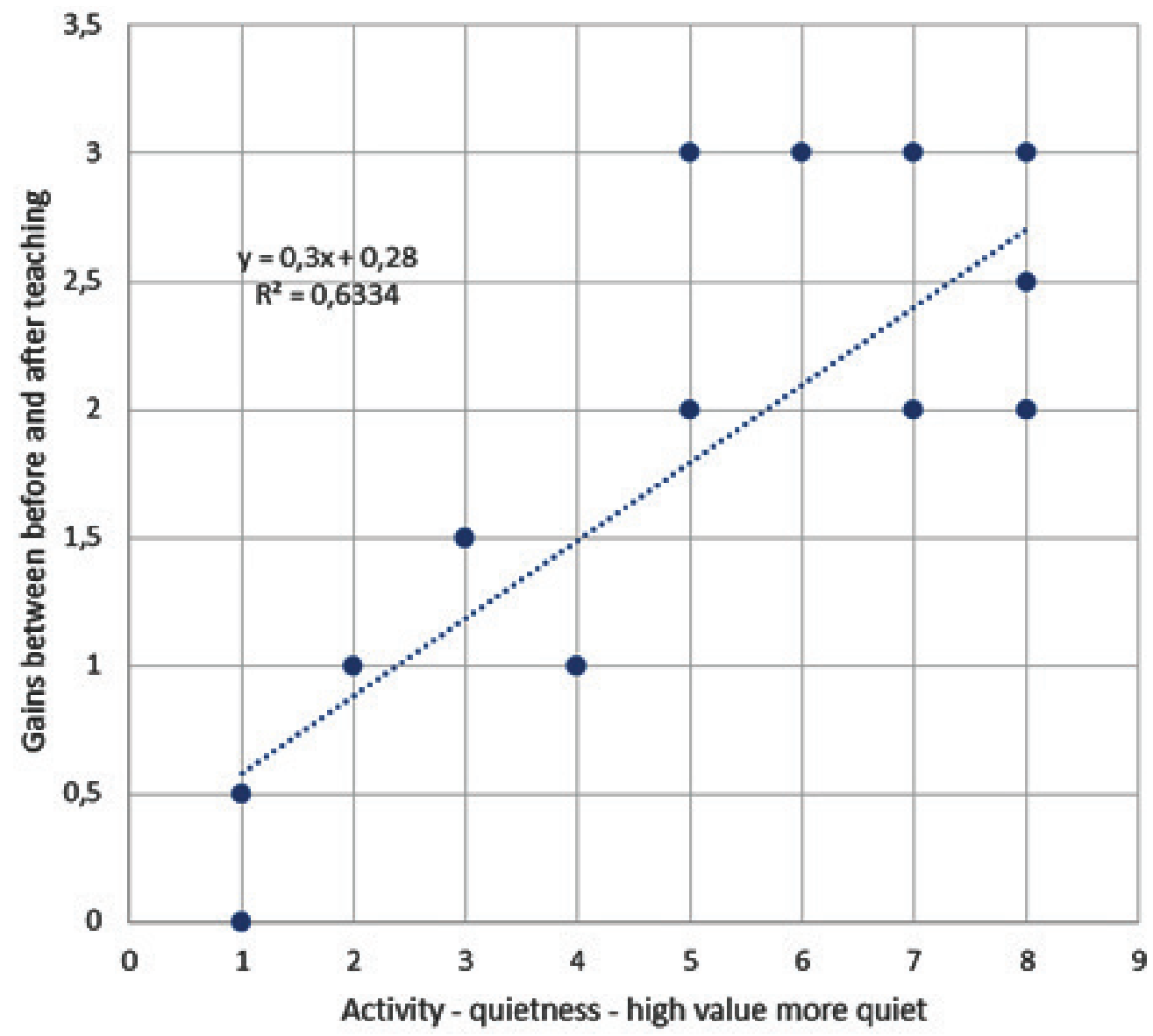

Figure 1. The gains as averaged over the two scales (bones and organs) plotted against the judged activity level, or quietness levels for 15 children. Note that points $(4,1)$ and $(8,2)$ are double.

The variation in the learning gains accounted for by quietness is around $65 \%, \mathrm{R} 2(1,13)=0.634$, $\mathrm{p}<0.001$. Thus, despite the fact that only 15 subjects are involved, the patterns shown by the results are statistically very robust. Non-parametric tests also give significant results, Kendall's tau_b = $0,601, p<01$. The relationship is positive showing that the more quiet the children were judged to be, the more they gained. The children classified as quiet gained more than the children classified as active as borne out by the statistical tests. The gains between the first and second drawing are shown by the Analysis of Variance to be robust, $\mathrm{F}(1,12)=86.7, \mathrm{p}<0.001$. Thus substantial learning clearly took place. There was no interaction between the type of material and time of testing, i.e. learning was not dependent on the material; $\mathrm{F}(1,12)=1.5, \mathrm{p}>0.2$. But there was an interaction between activity group and learning; $\mathrm{F}(2,12)=6.7$, $\mathrm{p}<0.011$, in line with the correlation discussed earlier, i.e. that the quiet children are showing more gains.

However, as these results only show the gains, it is conceivable that the active children understood more than the quiet children and the data simply reflect a ceiling effect. In other words, the active children might have more knowledge to start with and there was an upper limit to the gains they 
could make. Fig. 2 shows data for two kinds of materials, bones and other organs, for the three activity groups. Visual inspection of the data does not support a ceiling effect interpretation and the data for the bones can be used to reject it, as the active bone group is nowhere near a ceiling after the learning period.

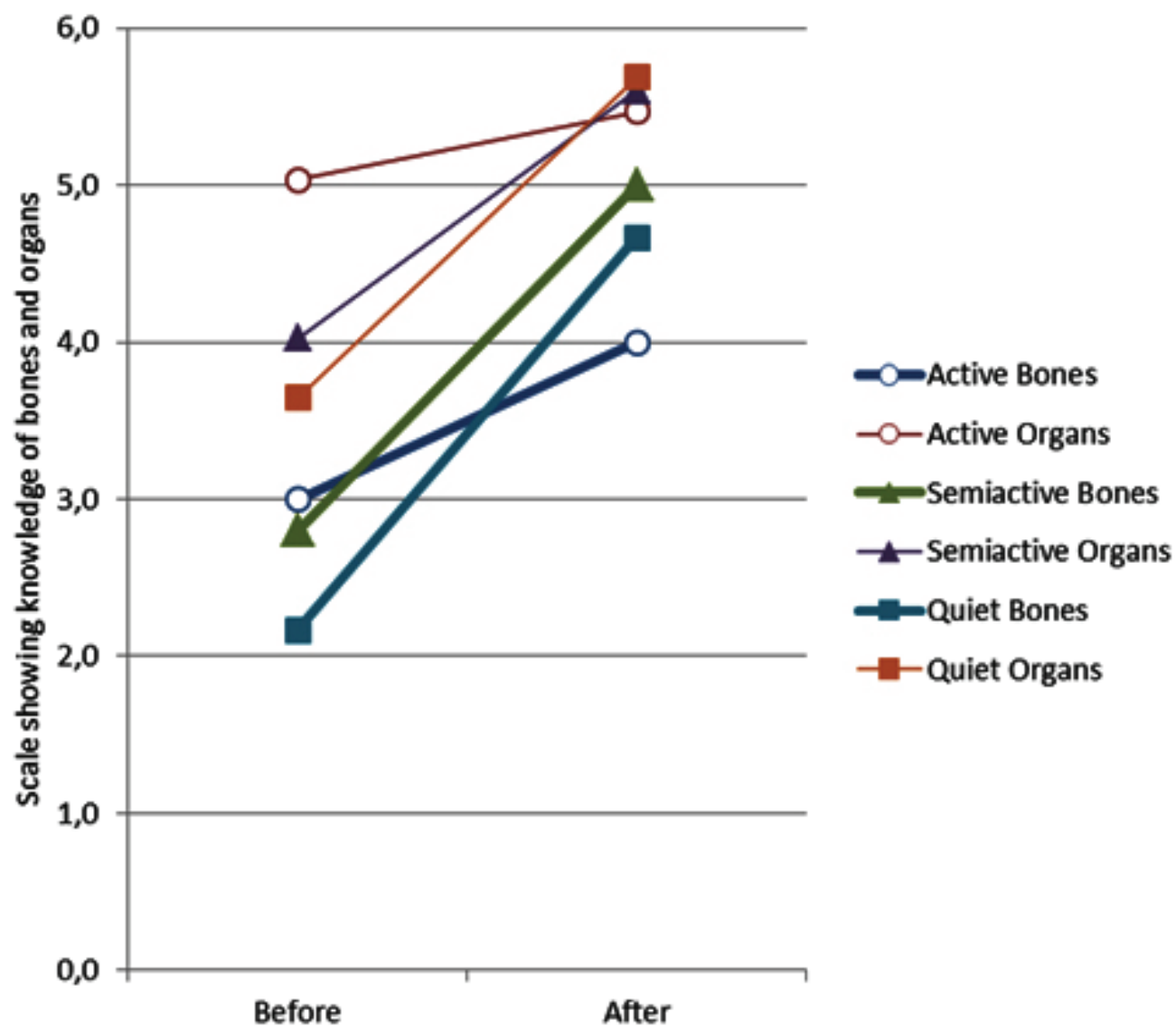

Figure 2. The performance by 15 children before and after the teaching period, shown for bones and organs, and the three activity groups.

The principal question concerned whether there was a differential learning effect depending on the children's participation in the class discussion. The data shows such an effect but in the opposite direction to that suggested by much of the literature. There are two concerns with regards to interpretation of the data in Fig. 2. One is that activity is only defined in terms of general participation in class discussion. The definition does not take into consideration activity manifested in other interactive tasks. The other is that even though the differences are robust as shown by the statistical analysis the final learning outcome for the different groups is at a similar level. Thus, even though the most quiet group, as here defined, showed most learning, the data does not clearly say that they know more or understand more in the end. However, both the overall correlation shown in Fig. 1, and the stable pattern in the data (which is borne out for both bones and other organs), shown in Fig. 2, underpin the basic results. Even though the data are clear, we still want to suggest that there are two levels of interpretation. One level is to say that adopting a quiet stance may be conducive to learning. But the second level of interpretation is a more cautious one which suggests that the more visibly active children are not learning more than the quieter ones. Or that quietness in the sense discussed here is not 
detrimental to learning. The small sample size is an issue, even though the statistical conclusions are quite clear, both for the generalisation of the data to other settings and cultures and to the population of pupils whether in Iceland or elsewhere (i.e. external validity concerns). The class in question is a typical Icelandic class for this age-group, with 20 pupils, actually slightly larger than average. With many countries in the region of 16-22 pupils in an average classroom, we don't think there are any reasons to consider that the small class size lessens the generalizability of the results to other settings. We note that the statistical analysis show that the results are robust in relative terms; the patterns are clearly significant. Nevertheless, we suggest a rather cautious stance when interpreting the results. Rather than drawing the strong conclusion that quietness, in the sense of not participating in discussion, is conducive to learning, we take the data to show, quite definitely, that not participating is certainly not necessarily detrimental to learning.

\section{Discussion}

The main outcome of the study was that some students made more progress than others in their learning and those who were normally active in class discussion related to the topic being taught, showed less gain than those who were less active in such discussion, who certainly benefitted substantially from the lessons. The results suggest that, in the literature, the importance of classroom talk for learning may have been overemphasised at the expense of active listening or attentiveness in the classroom. Furthermore, the results suggest that the idea of classroom talk could be enriched by a greater awareness that perhaps good listening may be of substantial value. A cautious interpretation is that, at least for some pupils, it is not necessary for them to participate in classroom discussions.

Thus we enter the arena of discussing what type of activity or what kind of interaction on behalf of the student facilitates learning. A wide range of teaching methods were used to teach about the human body, e.g. class discussion, short introduction (mini lectures), practical work, investigations, interactive activities on the Internet, drama and demonstrations. Usually the lesson started with an open question, followed by a discussion where the teacher involved the children. The teacher also used demonstrations with visual aids to explain certain issues and involved the children in a lot of practical work. The type of class discussion depended on the nature of the teacher's interaction and the questions she put forward. Sometimes the children shared factual recall and other times they shared responses and ideas that perhaps altered their thinking or enabled them to construct new ideas. It is difficult to tell which of the activities the children participated in or were exposed to, had the most effect on the development of their ideas because none of these were used in isolation.

It may be inappropriate, as Mayer (2009) points out, to assume that learning requires particular teaching methods, such as hands-on activity or as in our case, participation in a discussion. Similarly, we can put a question mark over the notion that teaching methods that foster reading, listening or watching, without any visible activity on the part of the children, may not be sufficient to promote learning. Experienced teachers sensibly use a variety of methods to obtain access to children's ideas and to help them learn. Listening, watching, drawing, and participating in various practical activities can also give children access to a teacher's ideas and, vice versa, some of these give the teacher access to children's ideas and thus become a part of the teaching process. The teacher in this study was deliberately trying to build on the children's ideas and extend their knowledge and understanding by using different ways of interacting with the children. But school activities don't always have to involve the teacher. Ogden (2000) and Fisher (2005) point out that information gained form working with peers can contribute to the development of children's ideas. In this study the children did a lot of practical work and hands-on activities as well as interactive activities in pairs on the computers in the classroom which required them to talk with each other and make collaborative decisions. Mercer and Littleton (2007) and Howe and Mercer (2007) similarly argue that it is of educational value when children are encouraged to explain their understanding and different points of view through discussion. Nevertheless, the findings of the present study suggest the need for refining the notion of active participation in class discussion and specifying the kinds of interaction that facilitate learning. Reda 
(2009) suggests that "there is more than one way to be a contributing member of a class, more than one way of learning and engaging" (p.171), a point also discussed by Chi et al. (2001) who note that learning does not occur only through direct personal participation in a dialogue.

The results of this study suggest that if 'being active' is a prerequisite for learning, activity may refer to cognitive activity that need not be visible behavioural activity. This complicates the issue of the nature and the role of activity, and carries with it the threat of a circular definition of activity, if it is not identifiable independently of the learning observed. It also begs the question if the terms 'active listener' or 'active watcher' benefit from the qualification 'active' in the absence of clear behavioural measures. Activity has to be independently specified, not only the activity of the learner, but also the activity demonstrated by the other children or the teacher. We do not know how important it is for quiet children that there is discussion among some of the children. More generally, the place and nature of classroom discussion has to be specified with reference to all children, as pointed out by Mercer and Littleton (2007).

The main conclusions of the study are both simple and interesting. The children were in a learning environment where the teacher used a variety of teaching methods even though we do not here present sufficient data to distinguish between the efficacies of the different methods. However, children that showed very clear signs of active participation in class discussion related to the topic did not learn any more than those who exhibited the opposite. In fact, the reverse seems to be the case. This requires a clarification of the theoretical notion of activity as well as a reassessment of the criteria used to measure activity with regard to 'being an active learner'. Collins (1996) emphasised that 'invisible' children have to be encouraged to be more assertive and find their voice in the classroom while the more vocal pupils have to be persuaded to talk less and give the quiet children a chance. Perhaps our teacher did this even though it may not have resulted in more vocal participation by the latter. According to Collins, 'being invisible' does not, however, always have a significant effect on children's learning and the results of this study show that the quiet children did not learn less than the others. Does this suggest that interaction in the guise of class discussion is not so important after all? The findings seem to refute any crude notion that visible interaction related to the classroom task is essential for learning. Is it then perhaps equally beneficial, or even better, just to sit and be quiet? This is not being suggested here, even though we don't know much about what the quiet children did in order to learn as much as they did with the material in question. It could be that the children's ideas developed because they listened the teacher's talk and their peers and thus related new information to their prior ideas and knowledge, possibly by reflection. We also want to emphasise that the visibly active children also showed progress. Therefore, the cautious conclusion is reiterated that not being visibly active is not detrimental to effective learning in the situation being investigated. Sometimes children are reluctant to express their ideas because they think they are wrong and are afraid of the attention their comments might receive. Osborne (1996) suggested that participation by thinking out loud should not be forced on the child but one should instead take positive steps towards trying to involve the quiet child in discussion. In a whole class discussion a small number of children usually come up with a sample of ideas and the teacher uses these to decide what ideas to build on. This was the case within the present study, though the teacher also used drawings made by all the children to investigate their ideas. To the extent that it may be sensible, as Harlen \& Qualter (2004) point out, to encourage teachers to use a constructivist approach to learning and teaching, the use of drawings, as in this study, discussion in small groups, concept maps, concept cartoons and peer or individual interviews may be equally or more important than class discussion.

The results of this study provide indirect support for Osborne (1996) when he suggests that the advocates of constructivist methods of teaching have chosen to over-emphasise cooperation and discussion-based activities in order to promote knowledge, ignoring the possibility that these other modes of teaching, such as telling, showing or demonstrating may be preferred by some students. This study calls for a more elaborate empirically based analysis of the type of activity that is conducive to lear- 
ning. This relates both to activity that can be attributed to the teacher and to the learner. Perhaps in particular to the learner as an individual and as a part of a group. Here the concept of "interthinking" used by Littleton and Mercer (2013) which combines visible and invisible use of language may turn out to be an important analytic tool. The study indicates that effective learning can take place in situations where the pupil appears to be passive and so supports the general analysis of Collins (1996) and Reda (2009). This does not in any way undermine the potential importance of covert cognitive activity. Our understanding of activity and interaction needs to be clarified and we may explore the differential usefulness of terms like participation, interaction and engagement as this may aid the clarification of what is important. The context may also work differently for different pupils. This study works with materials (drawings) that are quite concrete and different material and different teaching methods may produce different results. We also note that a nonverbal dependent variable was used and this needs to be compared to results that use assessment of verbal output, as the phenomenon under investigation is essentially an overt verbal activity. A study exploring the variables of activity, various types of engagement or interaction and different materials, taking into account individual differences and different assessment scales, would contribute substantially to the guidelines teachers need for conducting important educational tasks in the sciences and in other subjects.

\section{REFERENCES}

Alexander, R. (2004). Towards Dialogic Teaching: Rethinking Classroom Talk. Cambridge: Dialogos.

Barnes, D. (2008). Exploratory Talk for Learning. In N. Mercer \& S. Hodgkinson (Eds.), Exploring Talk in Schools. London SAGE.

Bruner, J. S., \& Haste, H. (1987). introduction. In J. S. Bruner \& H. Haste (Eds.), Making sense: The child's construction of the world. London: Methuen.

Burns, C., \& Myhill, D. (2004). Interactive or inactive? A consideration of the nature of interaction in whole class teaching. Cambridge Journal of Education, 34(1), 35-49.

Chi, M., Siler, S., Jeong, H., Yamauchi, T., \& Haussmann, R. (2001). Learning from human tutoring. Cognitive Science, 25, 471-533.

Collins, J. (1996). The quiet child. London: Cassell.

Cornu, R. L., Peters, J., \& Collins, J. (2003). What are the characteristics of constructivist learning cultures? British Educational Research Association Annual Conference

Fisher, R. (1995). Teaching Children to Learn (1st ed.). Cheltenham: Stanley Thornes.

Fisher, R. (2005). Teaching children to learn (2nd ed.). Cheltenham: Nelson Thornes Ltd.

Harlen, W., \& Qualter, A. (2004). The Teaching of Science in Primary School (4th ed.). London: David Fulton Publishers.

Hedegaard, M. (1999). The Influence of Societal Knowledge Traditions on Children's Knowledge Traditions on Children's Thinking and Conceptual Development. In M. Hedegaard \& J. Lompscher (Eds.), Learning Activity and Development. Aarhus: Aarhus University Press.

Howe, C., \& Mercer, N. (2007). Children's social development, peer interaction and classroom learning Primary Review Research Survey 2/1b. Cambridge: University of Cambridge Faculty of Education.

Keogh, B., \& Naylor, S. (1996). Teaching and learning in science: a new perspective. Paper presented at the BERA Conference, Lancaster.

Keogh, B., \& Naylor, S. (2004). Children's ideas, children's feelings. Primary Science Review, 82, $18-20$.

Littleton, K., \& Mercer, N. (2013). Interthinking : putting talk to work. Abingdon, Oxon: Routledge.

Mayer, R. C. (2009). Construcivism as a Theory of Learning versus Constructivism as a Prescription for Instruction. New York Routledge.

Mercer, N. (1995). The guided construction of knowledge. Clevedon: Multilingual Matters.

Mercer, N. (2000). Words and minds. London: Routledge.

Mercer, N., \& Daves, L. (2008). The value of exploratory talk. In N. Mercer \& S. Hodgkinson (Eds.), 
Exploring talk in school. London: SAGE.

Mercer, N., \& Littleton, K. (2007). Dialogue and the development of children's thinking. A sociocultural approach. London: Routhledge.

Myhill, D. (2003). Principled Understanding? Teaching the Active and Passive Voice. Language and Education, 17(5), 355-369.

Myhill, \& Brackley. (2004). Making connections: Teachers' use of children's prior knowledge in whole class discourse. British Journal of Educational Studies, 52(3), 263-275.

Ogden, L. (2000). Collaborative tasks, collaborative children: An analysis of reciprocity during peer interaction at Key Stage 1. British Educational Research Journal, 26(2), 211-226.

Osborne, J. (1996). Beyond Constructivism. Science Education, 8o(1), 52-82.

Óskarsdóttir, G. (2006). The development of children's ideas about the body: How these ideas change in a teaching environment. $\mathrm{PhD}$, University of Iceland, Reykjavík.

Reda, M. M. (2009). Between speaking and silence. New York: State University of New York Press.

Reiss, \& Tunnicliffe. (1999). Children's knowledge of the human skeleton. Primary Science Review, 60 (Nov/Dec), 7-10.

Scott, P. (2008). Talking a way to understanding in science classrooms. In N. Mercer \& S. Hodgkinson (Eds.), Exploring talk in school. London: SAGE.

Tobias, S., \& Duffy, T. M. (2009). Constructivist instruction : success or failure? London: Routledge.

Tunnicliffe, S. D., \& Reiss, J. M. (1999). Learning about skeletons and other organ systems of vertebrate animals. Science Education International, 10(1), 29-33.

Vygotsky, L. (1978). Mind in Society: the development of higher psycological processes. Cambridge: Harward University Press.

Vygotsky, L. (1986). Thought and language. Cambridge: The MIT Press.

Wilson, B. G., \& Myers, K. M. (2000). Situated Cognition in Theoretical and Practical Context. In D. H. Jonassen \& S. M. Land (Eds.), Theoretical Foundations of Learning Environments. New Jersey: LEA. 